\title{
RNA Synthesis
}

National Cancer Institute

\section{Source}

National Cancer Institute. RNA Synthesis. NCI Thesaurus. Code C19018.

Used to denote the transcription of DNA into RNA. The biochemical machinery includes sequence-specific DNA binding proteins that directly act in the regulation of the transcription process, other protein factors that participate in the assembly of the transcription complex, and RNA polymerase. 